\title{
Dairy consumption and ovarian cancer risk in the Netherlands Cohort Study on Diet and Cancer
}

\author{
M Mommers*,', LJ Schouten', RA Goldbohm² and PA van den Brandt' \\ 'Department of Epidemiology, NUTRIM, Maastricht University, PO Box 616, Maastricht 6200 MD, The Netherlands; ${ }^{2}$ Department of Food and \\ Chemical Risk Analysis, TNO Quality of Life, Zeist, The Netherlands
}

\begin{abstract}
Ovary cancer risk in relation to consumption of dairy products was investigated using a self-administered questionnaire on dietary habits and other risk factors for cancer, which was completed in 1986 by 62573 postmenopausal women participating in the Netherlands Cohort Study. Follow-up for cancer was implemented by annual record linkage with the Netherlands Cancer Registry and a nationwide pathology registry. After 11.3 years of follow-up, data of 252 incident epithelial ovarian cancer cases and 2216 subcohort members were available for analysis. No association was seen between consumption of milk, yoghurt, cheese or fermented dairy products and ovarian cancer risk. The multivariable adjusted relative risk of epithelial ovarian cancer for women in the highest compared to the lowest quintile of intake of lactose or dairy fat was $0.93(95 \%$ confidence interval $(\mathrm{Cl})=0.60-1.45$; $\left.P_{\text {trend }}=0.32\right)$ and $1.53\left(95 \% \mathrm{Cl}=1.00-2.36 ; P_{\text {trend }}=0.1 \mathrm{I}\right)$, respectively. Lactose or dairy fat intakes were not associated with serous ovarian cancer risk. Our results do not support an association between consumption of dairy products or lactose intake and ovarian cancer.
\end{abstract}

British Journal of Cancer (2006) 94, 165 - 170. doi: I0.1038/sj.bjc.6602890 www.bjcancer.com

Published online 22 November 2005

(C) 2006 Cancer Research UK

Keywords: ovarian neoplasms; dairy products; milk; lactose; dairy fat

Ovarian cancer ranks fifth as the most common malignancy among women in Europe, with approximately 34500 newly diagnosed ovarian cancer cases in 1998 (Ferlay et al, 1999). Due to its late detection in many cases, survival rates are low.

In an ecological analysis, ovarian cancer incidence and per capita milk consumption have been found to be correlated among populations (Cramer, 1989). The results from case-control and prospective cohort studies regarding milk consumption and ovarian cancer risk have been inconsistent (Mettlin and Piver, 1990; Webb et al, 1998; Kushi et al, 1999; Cramer et al, 2000; Goodman et al, 2002; Fairfield et al, 2004; Larsson et al, 2004; Qin et al, 2005).

As a possible mechanism underlying the effect of milk consumption on ovarian cancer risk, metabolites of the milksugar lactose have been suggested (Cramer, 1989; Cramer et al, 1989). With the exception of two case-control studies that reported a protective effect (Herrinton et al, 1995; Goodman et al, 2002), most studies found no statistically significant effect of high lactose intake on overall ovarian cancer risk (Engle et al, 1991; Webb et al, 1998; Kushi et al, 1999; Cramer et al, 2000; Cozen et al, 2002; Fairfield et al, 2004). On the other hand, for serous epithelial ovarian tumours, a positive association with lactose intake has been observed (Fairfield et al, 2004; Larsson et al, 2004). Most attention has been given to lactose even though other components of milk and milk products may be involved, such as

\footnotetext{
*Correspondence: Dr M Mommers;

E-mail: Monique.Mommers@epid.unimaas.nl

Received 30 August 2005; revised 13 October 2005; accepted 31 October 2005; published online 22 November 2005
}

dairy fat (Cramer et al, 1984; Qin et al, 2005), which may also be considered as a candidate risk factor because it is believed to exert an effect through hormone-related mechanisms.

To investigate whether consumption of dairy products (such as milk, yoghurt or cheese), its components (such as lactose or dairy fat) or its processing (fermentation) is associated with epithelial ovarian cancer risk, we used data from a large prospective cohort study conducted among postmenopausal women in the Netherlands, a country with high consumption of dairy products.

\section{MATERIALS AND METHODS}

\section{The cohort}

The Netherlands Cohort Study on Diet and Cancer is a prospective cohort study that started in September 1986 with the enrolment of 120852 subjects (62 573 females) aged between 55 and 69 years from 204 municipalities with computerised population registries, located throughout the country. A detailed description of the study design has been published elsewhere (van den Brandt et al, 1990a). In brief, a case-cohort approach was used for data processing and analysis. Cases were enumerated from the entire cohort, whereas accumulated person-years for the entire cohort were estimated using a subcohort of 5000 participants, 2589 of whom were females. The subcohort was randomly sampled from the cohort after baseline exposure measurement and followed up biennially for vital status information. After 11.3 years of follow-up, information on vital status was available for all female subcohort members. After exclusion of women with prevalent cancer (other than skin cancer) at baseline and those who at baseline had 
reported to have undergone an oophorectomy, 2406 female subcohort members remained available for analyses.

\section{Identification of cases}

Incident cancer cases were identified by computerised record linkage of the entire cohort to the regional cancer registries and to the nationwide network and registry of histo- and cytopathology in the Netherlands (PALGA) (van den Brandt et al, 1990a,b). The completeness of cancer follow-up has previously been estimated to be over $95 \%$ (Goldbohm et al, 1994b). During 11.3 years of followup, 300 incident, microscopically confirmed, primary ovarian cancer cases (ICD-O-3:C56.9) were identified. After excluding nonepithelial tumours $(n=9)$ and borderline invasive epithelial tumours $(n=9), 282$ invasive epithelial tumour cases remained available for analyses. Of these 282 epithelial ovarian cancers, 138 were serous carcinoma (ICD-O: 8260, 8441-8462, 9014).

\section{Questionnaire}

Information on dietary habits and such potential confounders, as smoking behaviour, reproductive history, and family history of cancer, was collected at baseline, from all cohort members, using a self-administered questionnaire. This included a 150 -item semiquantitative food frequency questionnaire, assessing regular food and beverage consumption in the year preceding the start of the study, which had been validated against a 9-day diet record, attaining Spearman's correlation coefficients of 0.60 for milk and milk products and 0.61 for cheese (Goldbohm et al, 1994a).

Data were obtained on frequency of dairy consumption (i.e., milk, yoghurt, cheese, curds, custard, oatmeal, butter, and pudding) and amount consumed on each consumption day (number of glasses for milk, number of slices of bread for cheese, and number of bowls for yoghurt, oatmeal, etc.). Consumption frequency was recorded using categories ranging from 'never or less than once per month' to 'six or seven times per week'.

Sources of fermented milk and milk products were investigated, including yoghurt, buttermilk, fat cheese, and curds; for nonfermented milk and milk products these were milk and cream. Sources of lactose were yoghurt, milk, chocolate, butter, dry curd, custard, pudding, and oatmeal.

\section{Data analyses}

After excluding subjects with incomplete or inconsistent dietary data (Goldbohm et al, 1994a), 252 ovarian cancer cases and 2216 subcohort members remained for analysis. Subjects were grouped into categories of dairy consumption (i.e., total milk, total yoghurt, and total cheese) and into quintiles of intake of lactose, dairy fat, fermented milk and milk products, and non-fermented milk and milk products, based on the distribution in the subcohort.

We examined if other risk factors (oral contraceptives use, (post)menopausal hormone therapy, parity, height, weight, body mass index, family history of ovarian or breast cancer, hysterectomy, age at menarche, age at menopause, tubal ligation, smoking behaviour, and socioeconomic status) were confounders in our data. Risk factors were considered to be confounders if they were associated with ovarian cancer risk, were associated with dairy intake, and, after inclusion in the model, changed the association of dairy with the risk of ovarian cancer by more than $10 \%$ compared to the model not including this factor. As a result, multivariable analyses included age (years), height (continuous), current cigarette smoker $(y / n)$, duration of cigarette smoking (years), number of cigarettes smoked daily (continuous), duration of oral contraceptives use (years), and parity (continuous) as confounders.

Person-years of follow-up were calculated for the female subcohort members from the date they returned the questionnaire
(September 1986) until the date of ovarian cancer diagnosis, death, or end of follow-up (December 1997).

Incidence rate ratios (RR) and corresponding 95\% confidence intervals (CI) for ovarian cancer risk were estimated in ageadjusted and multivariate case-cohort analyses using Cox proportional hazards model (Cox, 1972) processed with the STATA statistical software package (Cleves et al, 2002). Standard errors were estimated using the robust Huber-White sandwich estimator to account for additional variance introduced by sampling from the cohort (Lin and Wei, 1989). The proportional hazards assumption was tested using the scaled Schoenfeld (1982) residuals. By fitting ordinal exposure variables as continuous terms, tests for dose-response trends in risks of ovarian cancer were carried out. Two-sided $P$-values are reported throughout the paper and considered statistically significant if $<0.05$.

\section{RESULTS}

During 11.3 years of follow-up of 62573 women, 282 epithelial ovarian cancer cases occurred, 252 of which were in women with complete and consistent dietary data. Of these 252 epithelial ovarian cancers, 126 were of the serous subtype.

Mean total dairy consumption as well as mean lactose intake were higher among women who reported ever use of oral contraceptives than among women who did not (Table 1), and was lower in current smokers than in nonsmokers. Taller women $(>170 \mathrm{~cm})$ also reported higher dairy consumption than those of lesser height $(<160 \mathrm{~cm})$. Lactose was highly correlated with total milk $(r=0.73)$ intake, especially with respect to nonfermented milk and milk products $(r=0.82)$. The correlation coefficient for dairy fat with total cheese was 0.46 and with total milk 0.27 .

Table 2 shows the age-adjusted and multivariable-adjusted RR for ovarian cancer according to categories of milk, yoghurt, or cheese consumption. After adjusting for confounders, women in the highest category of total milk $(\mathrm{RR}=0.98,95 \% \mathrm{CI}=0.65-1.48)$, total yoghurt $(\mathrm{RR}=0.87,95 \% \mathrm{CI}=0.59-1.28)$, or total cheese $(\mathrm{RR}=1.06,95 \% \mathrm{CI}=0.54-2.08)$ consumption were not at greater risk of ovarian cancer compared to women in the lowest consumption category. Serous epithelial ovarian cancers did not show an association with the dairy products investigated.

No statistically significant association was found with consumption of fermented or nonfermented milk and milk products (Table 2). Only the highest quintile of dairy fat intake was associated with increased risk when compared to the lowest quintile of intake $\left(\mathrm{RR}_{\mathrm{Q} 5}\right.$ vs $\mathrm{Q} 1=1.53,95 \% \quad \mathrm{CI}=1.00-2.36$; $\left.P_{\text {trend }}=0.11\right)$. This positive association was not seen for serous epithelial ovarian cancer $\left(\mathrm{RR}_{\mathrm{Q} 5}\right.$ vs $\left.\mathrm{Q} 1=0.76,95 \% \mathrm{CI}=0.42-1.39\right)$. The numbers of other subtypes of epithelial ovarian cancer were too small to allow for separate analyses. The frequencies of all subtypes of epithelial ovarian cancer were uniformly distributed over the fat quintiles, with the exception of the endometrioid subtype $(n=24)$, for which the frequency increased over the quintiles of dairy fat intake (data not shown).

Higher intake of lactose showed no association or at most a tendency towards decreased risk (for all ovarian cancers $P_{\text {trend }}=0.32$ and for serous ovarian cancer $P_{\text {trend }}=0.11$ ), largely due to a significantly decreased risk in the third quintile of intake for all epithelial ovarian cancers $\left(\mathrm{RR}_{\mathrm{Q} 3} v_{\mathrm{Q}} \mathrm{Q} 1=0.62,95 \% \mathrm{CI}=0.39\right.$ $0.98)$ as well as for serous ovarian cancers $\left(\mathrm{RR}_{\mathrm{Q} 3}\right.$ ss $\mathrm{Q} 1=0.45,95 \%$ $\mathrm{CI}=0.22-0.91)$. The multivariable adjusted $\mathrm{RR}$ for lactose of the epithelial ovarian cancers or its serous subtype did not importantly change after additionally adjusting for dietary fat, energy, or total milk intake, respectively.

In addition, we investigated if the presence of subclinical disease at baseline had influenced our results, and re-analysed our data after excluding cases and subcohort members with less than 2 years of follow-up; this did not substantially change our results. 
Table I Mean ( \pm s.d.) daily consumption of dairy products and lactose intake in the subcohort $(n=2216)$, according to potential risk factors for ovarian cancer (recorded at baseline), Netherlands Cohort Study on Diet and Cancer, 1986- 1997

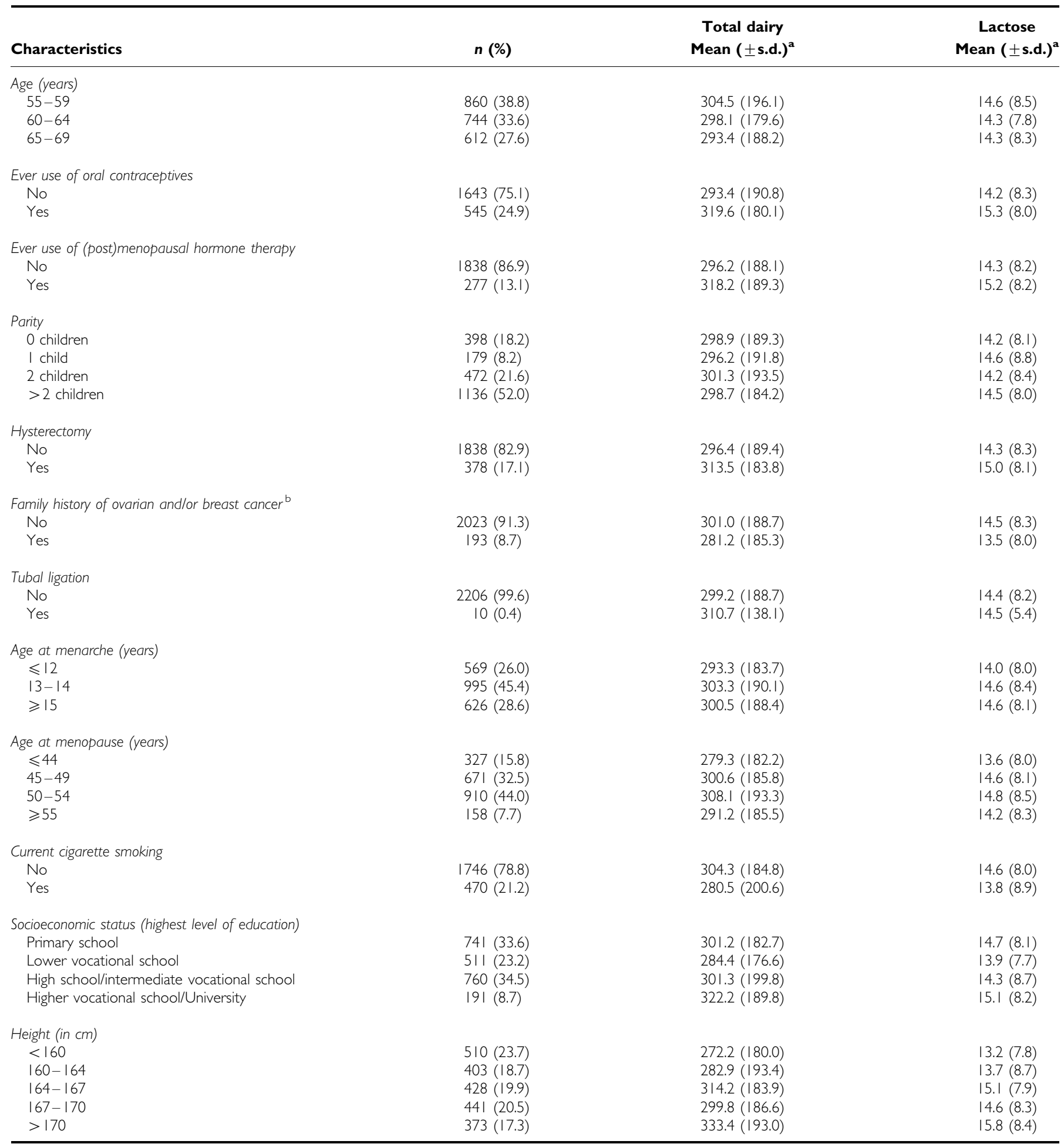

Due to missings, numbers do not always add up to the total. ${ }^{a}$ In $g$ day ${ }^{-1}$. b In first degree relatives (mother, sister, daughter).

\section{DISCUSSION}

In this large prospective cohort study of postmenopausal Dutch women, no relation between consumption of milk, yoghurt, or cheese and ovarian cancer risk was seen. In contrast to the previously reported results from cohort studies (Fairfield et al,
2004; Larsson et al, 2004), in the present study, lactose intake was not positively associated with serous ovarian cancer. The highest quintile of dairy fat intake was associated with increased ovarian cancer risk when compared to the lowest intake, but no statistically significant dose-response relation was observed and it was absent for serous ovarian cancers. 
Table 2 Age-adjusted and multivariate RRs and $95 \% \mathrm{Cl}$ for ovarian cancer according to dairy consumption and intake of fat or lactose, Netherlands Cohort Study on Diet and Cancer, 1986-1997

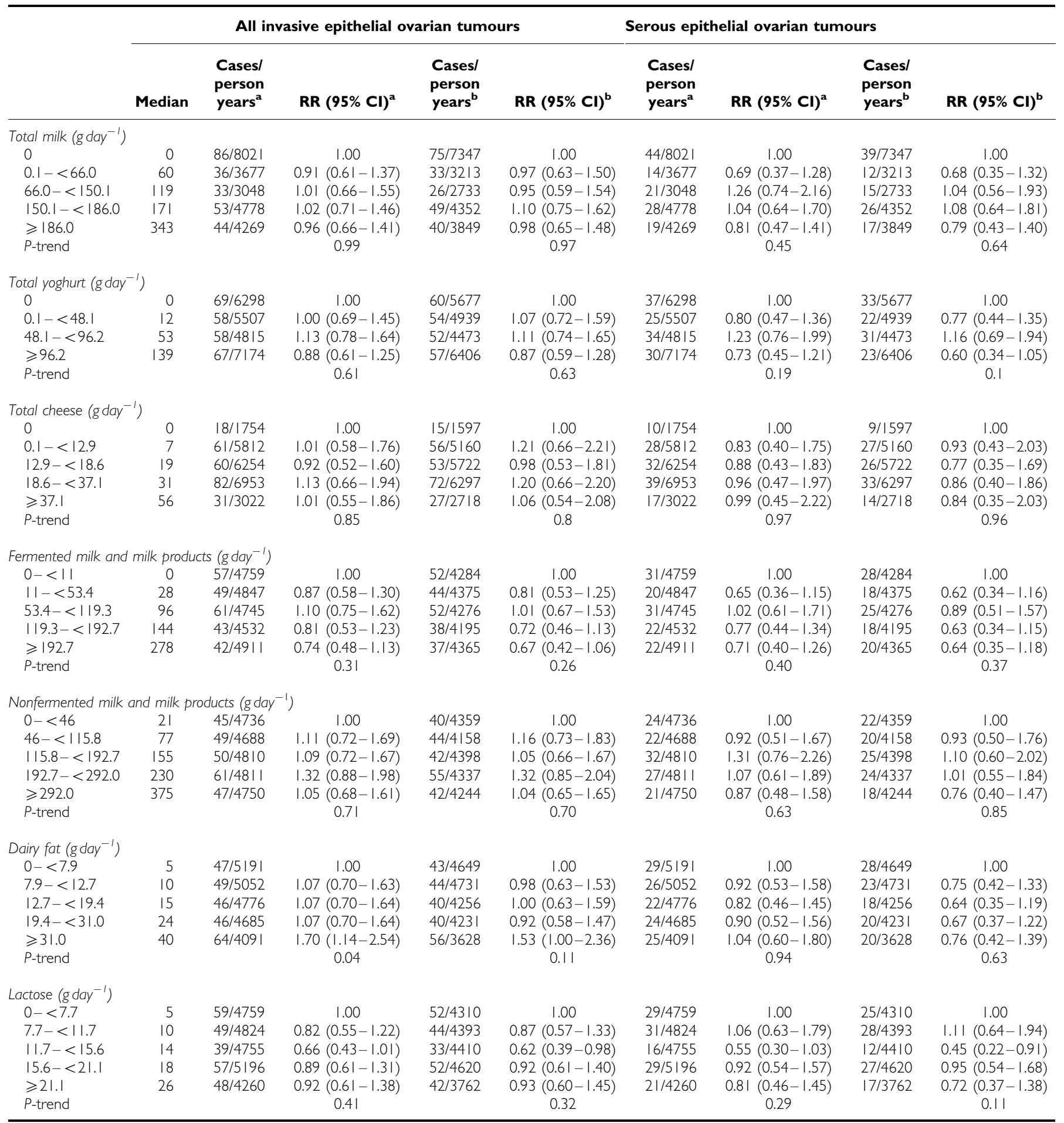

${ }^{a}$ Age-adjusted analyses. ${ }^{b}$ Analyses adjusted for age (years), height (cm), current cigarette smoker (y/n), duration of cigarette smoking (years), number of cigarettes smoked daily, duration of oral contraceptive use (years) and parity (continuous), and fermented dairy products and nonfermented dairy products for each other.

Contrary to our results, the Swedish (Larsson et al, 2004) and the US cohort studies (Kushi et al, 1999; Fairfield et al, 2004) have reported increased risk with higher consumption of milk. In the Swedish Mammography Cohort Study, the risk was 1.3 (95\% $\mathrm{CI}=0.9-1.9)$ for women who consumed $\geqslant 2$ glasses milk per day compared to never or seldom users, and this association was stronger $(\mathrm{RR}=2.0,95 \% \mathrm{CI}=1.1-3.7)$ for serous ovarian cancer (Larsson et al, 2004). In the Nurses' Health Study, when skim or low-fat and whole milk were considered separately, a significant positive trend was only observed for skim or low-fat milk (Fairfield et al, 2004). Higher consumption of skim milk was also found to increase the risk of ovarian cancer in the Iowa Women's Health 
Study (Kushi et al, 1999). However, results from case-control studies have been inconsistent, some reporting no association with whole milk (Cramer et al, 2000; Goodman et al, 2002) or skim or low-fat milk (Cramer et al, 2000), whereas a positive association with whole milk and a negative association with skimmed milk have also been found (Mettlin and Piver, 1990; Webb et al, 1998). For consumption of yoghurt, a positive association with serous ovarian cancer was reported from the Nurses' Health Study, and for consumption of hard cheese the risk of all epithelial ovarian tumours was decreased with higher consumption (Fairfield et al, 2004). The results of our prospective cohort study are in accordance with results from previous case-control studies (Cramer et al, 2000; Goodman et al, 2002) in showing no effect of higher yoghurt or cheese consumption on ovarian cancer risk.

Lactose or dairy fat has been considered as the explanation for earlier findings of increased ovarian cancer risk with higher consumption of dairy products. In this regard, lactose and in particular its metabolite galactose have attracted most attention, since ovaries may be prone to galactose toxicity owing to their high local concentration of the galactose-metabolising enzyme galactose-1-phosphate uridyltransferase, as well as their high tissue-specific activity of this enzyme (Xu et al, 1989; Larsson et al, 2004). Galactose is believed to be ootoxic or to induce high concentrations of gonadotropins (Cramer, 1989; Cramer et al, 1989). Although in three prospective studies no statistically significant associations between all epithelial ovarian cancers and lactose intake has been reported (Kushi et al, 1999; Fairfield et al, 2004; Larsson et al, 2004), two of these studies did suggest that lactose might adversely affect serous ovarian cancer risk (Fairfield et al, 2004; Larsson et al, 2004). Our study results however suggest no association with lactose intake or might even indicate an inverse association. Inverse associations between lactose intake and ovarian cancer have previously been reported from casecontrol studies (Herrinton et al, 1995; Goodman et al, 2002). Differences in level of lactose intake may have contributed to the discrepancy among cohort studies, since the Netherlands has a high consumption of dairy products. However, categories of lactose intake did not differ largely among these studies although the median intake in the lowest categories was somewhat higher in the present Dutch than in the Swedish or US studies. The comparable number of ovarian cancer cases as well as of the serous subtype in the cohort studies would not explain the negative findings of the present study. Although height was found to be a risk factor in our cohort (Schouten et al, 2003), omitting height from the multivariate model did not change the RRs for total milk consumption or for lactose intake. Moreover, when included in the models, the interaction terms (height $*$ lactose and height*total milk, respectively) did not reach statistical significance, thereby excluding height as an effect modifier. On the other hand, dairy fat intake was associated with risk in our study; women in the highest quintile of dairy fat intake were at $1.53(95 \% \mathrm{CI}=1.00-2.36)$ times higher risk than those in the lowest quintile. In 1990, Mettlin and Piver suggested that it was not the lactose content of milk but rather its fat content that was responsible for the association. High consumption of fat may influence ovarian cancer risk through increased oestrogen levels (Qin et al, 2005). Since this effect was absent for serous ovarian cancer, we hypothesise that dairy fat may present a risk for ovarian cancers other than serous, such as the endometrioid subtype, but their small number $(n=24)$ did not allow for separate analysis.

Consumption of fermented dairy products was not associated with risk in our study. Fermented milk bacteria potentially have protective effects, because they provide a detoxification mechanism through the binding of heterocyclic aromatic amines directly to their cell walls (Knasmuller et al, 2001). Milk and other dairy products however also contain calcium and various vitamins, and moreover may be contaminated by pesticides; none of these were covered in the present study.

The important strengths of our study are its prospective design, reducing the potential for recall bias and the nearly complete follow-up of cases as well as of subcohort members, making selection bias unlikely. Moreover, we were able to control for confounding by most known ovarian cancer risk factors. Measurement error may have influenced our results, but we expect this to be random and to have at most biased our results towards the null. In addition, multivariate modelling itself may have added some uncertainty through measurement error affecting confounders as well (Schatzkin and Kipnis, 2004). We used a food frequency questionnaire to measure consumption of milk and milk products, which, in a validation study, was found to correlate well with a 9-day diet record (Goldbohm et al, 1994a). There was a relatively high correlation between lactose and total milk $(r=0.73)$, but the risk estimate with lactose intake did not importantly change when milk consumption was included in the analysis. In addition, adjusting for dietary fat or total energy did not significantly change the RR for lactose.

In this prospective cohort study of postmenopausal women, consumption of milk, yoghurt or cheese was not associated with ovarian cancer risk. Contrary to previous findings, lactose intake was not associated with risk of serous ovarian cancer or even showed a slight inverse association. The highest quintile of dairy fat intake was associated with overall, but not with serous, ovarian cancer risk when compared to the lowest intake.

\section{ACKNOWLEDGEMENTS}

The study was financially supported by the World Cancer Research Fund-UK (Grant 2003/30). We are indebted to the participants of this study and further wish to thank the cancer registries (IKA, IKL, IKMN, IKN, IKO, IKR, IKST, IKW, IKZ, and VIKC) and the Netherlands nationwide registry of pathology (PALGA); Dr A Volovics and Dr A Kester for statistical advice; $S$ van de Crommert, J Nelissen, C de Zwart, M Moll, W van Dijk, M Janssen, and A Pisters for assistance; $\mathrm{H}$ Brants for determining lactose intake; $\mathrm{H}$ van Montfort, T van Moergastel, L van den Bosch, and R Schmeitz for programming assistance.

\section{REFERENCES}

Cleves MA, Gould WW, Gutierrez RG (2002) An Introduction to Survival Analysis Using Stata. Texas: Stata Press

Cox DR (1972) Regression models and life-tables (with discussion). $J R$ Statist Soc B 34: 187-220

Cozen W, Peters R, Reichardt JK, Won N, Felix JC, Wan P, Pike MC (2002) Galactose-1-phosphate uridyl transferase (GALT) genotype and phenotype, galactose consumption, and the risk of borderline and invasive ovarian cancer (United States). Cancer Causes Control 13: 113-120

Cramer DW (1989) Lactase persistence and milk consumption as determinants of ovarian cancer risk. Am J Epidemiol 130: 904-910
Cramer DW, Greenberg ER, Titus Ernstoff L, Liberman RF, Welch WR, Li E, Ng WG (2000) A case - control study of galactose consumption and metabolism in relation to ovarian cancer. Cancer Epidemiol Biomarkers Prev 9: 95-101

Cramer DW, Harlow BL, Willett WC, Welch WR, Bell DA, Scully RE, Ng WG, Knapp RC (1989) Galactose consumption and metabolism in relation to the risk of ovarian cancer. Lancet 2: 66-71

Cramer DW, Welch WR, Hutchison GB, Willett W, Scully RE (1984) Dietary animal fat in relation to ovarian cancer risk. Obstet Gynecol 63: $833-838$ 
Engle A, Muscat JE, Harris RE (1991) Nutritional risk factors and ovarian cancer. Nutr Cancer 15: 239-247

Fairfield KM, Hunter DJ, Colditz GA, Fuchs CS, Cramer DW, Speizer FE, Willett WC, Hankinson SE (2004) A prospective study of dietary lactose and ovarian cancer. Int J Cancer 110: 271-277

Ferlay J, Bray F, Sankila R, Parkin D (1999) EUCAN: Cancer Incidence, Mortality and Prevalence in the European Union 1997, version 4.1, Vol. IARC CancerBase No. 4. Lyon, France: IARC Press

Goldbohm RA, van den Brandt PA, Brants HA, van't Veer P, Al M, Sturmans F, Hermus RJ (1994a) Validation of a dietary questionnaire used in a large-scale prospective cohort study on diet and cancer. Eur J Clin Nutr 48: 253-265

Goldbohm RA, van den Brandt PA, Dorant E (1994b) Estimation of the coverage of Dutch municipalities by cancer registries and PALGA based on hospital discharge data. Tijdschr Soc Gezondheidsz 72: 80-84

Goodman MT, Wu AH, Tung KH, McDuffie K, Kolonel LN, Nomura AMY, Terada K, Wilkens LR, Murphy S, Hankin JH (2002) Association of dairy products, lactose, and calcium with the risk of ovarian cancer. Am J Epidemiol 156: $148-157$

Herrinton LJ, Weiss NS, Beresford SA, Stanford JL, Wolfla DM, Feng Z, Scott CR (1995) Lactose and galactose intake and metabolism in relation to the risk of epithelial ovarian cancer. Am J Epidemiol 141: $407-416$

Knasmuller S, Steinkellner H, Hirschl AM, Rabot S, Nobis EC, Kassie F (2001) Impact of bacteria in dairy products and of the intestinal microflora on the genotoxic and carcinogenic effects of heterocyclic aromatic amines. Mutat Res 480-481: 129-138

Kushi LH, Mink PJ, Folsom AR, Anderson KE, Zheng W, Lazovich D, Sellers TA (1999) Prospective study of diet and ovarian cancer. Am J Epidemiol 149: 21 -31
Larsson SC, Bergkvist L, Wolk A (2004) Milk and lactose intakes and ovarian cancer risk in the Swedish Mammography Cohort. Am J Clin Nutr 80: $1353-1357$

Lin DY, Wei LJ (1989) The robust inference for the Cox Proportional Hazards Model. J Am Statist Assoc 84: 1074- 1078

Mettlin CJ, Piver MS (1990) A case-control study of milk-drinking and ovarian cancer risk (see comments). Am J Epidemiol 132: 871-876

Qin LQ, Xu JY, Wang PY, Hashi A, Hoshi K, Sato A (2005) Milk/dairy products consumption, galactose metabolism and ovarian cancer: metaanalysis of epidemiological studies. Eur J Cancer Prev 14: 13 - 19

Schatzkin A, Kipnis V (2004) Could exposure assessment problems give us the wrong answers to nutrition and cancer questions?. J Natl Cancer Inst 96: $1564-1565$

Schoenfeld D (1982) Partial residuals for the proportional hazards regression model. Biometrika 69: 239-241

Schouten LJ, Goldbohm RA, van den Brandt PA (2003) Height, weight, weight change, and ovarian cancer risk in the Netherlands cohort study on diet and cancer. Am J Epidemiol 157: 424-433

van den Brandt PA, Goldbohm RA, van't Veer P, Volovics A, Hermus RJ, Sturmans F (1990a) A large-scale prospective cohort study on diet and cancer in The Netherlands. J Clin Epidemiol 43: 285-295

van den Brandt PA, Schouten LJ, Goldbohm RA, Dorant E, Hunen PM (1990b) Development of a record linkage protocol for use in the Dutch Cancer Registry for Epidemiological Research. Int $J$ Epidemiol 19: $553-558$

Webb PM, Bain CJ, Purdie DM, Harvey PW, Green A (1998) Milk consumption, galactose metabolism and ovarian cancer (Australia). Cancer Causes Control 9: 637-644

Xu YK, Ng WG, Kaufman FR, Lobo RA, Donnell GN (1989) Galactose metabolism in human ovarian tissue. Pediatr Res 25: 151-155 